
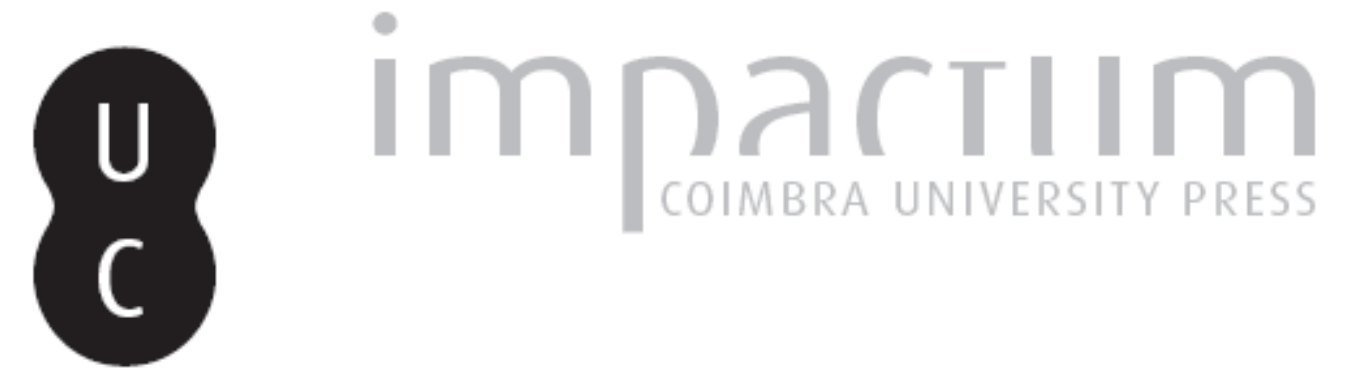

\title{
A estratégia internacional de redução de desastres
}

Autor(es): $\quad$ Rodrigues, Teresa

Publicado por: Associação Portuguesa de Riscos, Prevenção e Segurança

URL persistente:

URI:http://hdl.handle.net/10316.2/36112

DOI:

DOI:http://dx.doi.org/10.14195/1647-7723_17_23

Accessed : $\quad$ 26-Apr-2023 11:55:43

A navegação consulta e descarregamento dos títulos inseridos nas Bibliotecas Digitais UC Digitalis, UC Pombalina e UC Impactum, pressupõem a aceitação plena e sem reservas dos Termos e Condições de Uso destas Bibliotecas Digitais, disponíveis em https://digitalis.uc.pt/pt-pt/termos.

Conforme exposto nos referidos Termos e Condições de Uso, o descarregamento de títulos de acesso restrito requer uma licença válida de autorização devendo o utilizador aceder ao(s) documento(s) a partir de um endereço de IP da instituição detentora da supramencionada licença.

Ao utilizador é apenas permitido o descarregamento para uso pessoal, pelo que o emprego do(s) título(s) descarregado(s) para outro fim, designadamente comercial, carece de autorização do respetivo autor ou editor da obra.

Na medida em que todas as obras da UC Digitalis se encontram protegidas pelo Código do Direito de Autor e Direitos Conexos e demais legislação aplicável, toda a cópia, parcial ou total, deste documento, nos casos em que é legalmente admitida, deverá conter ou fazer-se acompanhar por este aviso.

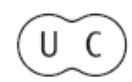




\section{territorium}

Riscos, Sociedade(s) e Segurança

Revista da Associação Portuguesa de Riscos, Prevenção e Segurança 2010 


\title{
NOTAS, NOTÍCIAS E RECENSÕES
}

\author{
A ESTRATÉGIA INTERNACIONAL DE REDUÇÃO DE DESASTRES ${ }^{1 *}$
}

Teresa Rodrigues

Doutoranda em Ciências do Ambiente (fct-unl) te.rodrigues@gmail.com

O desafio colocado pelos desastres de origem natural, levou a comunidade internacional a reconhecer que a Humanidade está perante uma ameaça global sem precedentes. Eventos extremos tais como, inundações, secas, tempestades, temperaturas extremas, tornados, furacões, incêndios e tsunamis, são frequentemente experiências dolorosas, causando grandes perdas de vidas humanas, destruindo modos de subsistência e deixando milhões de pessoas devastadas perante 0 imperativo dever de recomeçar de novo com o que resta. Tais acontecimentos têm construído uma nova percepção de risco e de custos globais em torno das consequências adversas destes fenómenos. Tudo leva a crer, sem alarmismos, nem pessimismos, apenas observando as estatísticas, que nas próximas décadas a nossa qualidade de vida poderá ser afectada, pelo impacto dos desastres.

Apesar de não ter sido ainda possível, estabelecer uma relação de causa/efeito entre as alterações climáticas e a frequência/ intensidade dos eventos extremos, existe um consenso cada vez mais alargado, acerca da relação intuitiva entre a adaptação às alterações climáticas e a redução de risco de desastres (RRD). Esta consciência tem motivado a comunidade internacional a agir no sentido de reduzir as vulnerabilidades físicas do ambiente mas cada vez mais as vulnerabilidades sociais ${ }^{1}$.

Se, por um lado, o Quarto Relatório do Intergovernamental Panel on Climate Change ${ }^{2}$ (IPCC 2007) reconhecia a importância da redução das vulnerabilidades relacionadas com os eventos extremos, foi indiscutivelmente em Dezembro de 2007 em Bali ${ }^{3}$, que o assunto ganhou relevância junto da Convenção Quadro das Nações Unidas sobre as Alterações Climáticas.

De acordo com os dados disponíveis, os desastres têm aumentado a sua frequência de forma muito significativa.
Entre 1991 e 2005, os desastres vitimaram cerca de 960.000 pessoas, afectando mais de 3.470 milhões e provocando prejuízos elevados 1.193 biliões de dólares ${ }^{4}$.

Em 2008, apesar de se observar uma redução de desastres reportados, os impactos humanos e económicos causados foram devastadores. Registaramse 321 desastres, mais de 235.000 pessoas morreram, 211,6 milhões foram afectadas e os custos económicos elevaram-se a 181 biliões de dólares ${ }^{5}$.

Dados recentes indicam que nos últimos 20 anos na Europa, ocorreram 953 desastres vitimando cerca de 88.671 pessoas, afectando mais de 20 milhões e provocando prejuízos elevados a 29 biliões de dólares. Estudos comparativos revelam que comparativamente a Africa, Ásia e América Latina, as perdas económicas per capita na Europa são mais elevadas devido a densidade de população e qualidade de vida ${ }^{6}$

Na Europa, no período de 1980-2008, as inundações e as tempestades representaram respectivamente $40 \%$ e $33 \%$ dos prejuízos económicos. A Itália e a Alemanha registaram maiores prejuízos económicos, a Espanha o maior número de vítimas e a Rússia o maior número de desastres (120 desastres).

Recentemente, em 28 de Janeiro de 2009, a tempestade Klaus afectou consideravelmente o sul da Europa (Espanha, França e Itália) vitimando 24 pessoas, e devastando milhares de hectares de floresta.

Em França, a tempestade deixou sem telefone e electricidade cerca de 1,7 milhões de habitações. A falha do sistema de distribuição eléctrica repercutiuse num conjunto de reacções em cadeia que agravaram consideravelmente os impactos directos da tempestade, tais como: problemas de acesso à água potável, avaria da sinalização rodoviária e ferroviária, comboios

1* 0 texto desta nota corresponde à comunicação apresentada ao V Encontro Nacional e I Congresso Internacional de Riscos e foi submetido para revisão em 25-05-2009, tendo sido aceite para publicação em 04-03-2010.

Esta nota é parte integrante da Revista Territorium, n. ${ }^{\circ}$ 17, 2010, @ Riscos, ISBN: 0872- 8941. 
paralisados, habitações privadas de aquecimento central, centrais telefónicas inoperacionais, as autoridades francesas confirmaram que foi necessário uma semana para restabelecer a distribuição eléctrica. Recorda-se que o mês de Janeiro foi marcado, em França, por uma onda de frio, que agravou consideravelmente a situação.

O reagrupamento das seguradoras "La Mutuelle" avaliou os custos da tempestade para as seguradoras aderentes em cerca 285 milhões de Euros, tendo sido emitidas 233.332 participações de sinistro. Relativamente ao seguro de habitação, foram recebidas 208,789 de participações de sinistro, e os prejuízos elevaram-se a 234,2 milhões de euros, os seguros de viaturas elevaramse a 25,2 milhões de euros e os seguros de empresas elevaram-se a 26,2 milhões de euros.

Relativamente aos prejuízos agrícolas, os custos elevaram-se a 44.1 milhões de euros. As indemnizações foram asseguradas pelo Fundo nacional de garantia das calamidades que desbloqueou um valor de 11,3 milhões de euros, sendo que um envelope de 4,5 milhões foi desbloqueado imediatamente. Dos 11 departamentos afectados, 5 departamentos concentram cerca de $70 \%$ e 1 departamento (La Gironde) concentrou 28\% do custo estimado da tempestade. Esta intervenção completou o plano de 25 milhões de euros disponibilizados em 12 de Fevereiro (menos de um mês após a tempestade.

$\mathrm{Na}$ sequência deste evento, a Comissão da UE emitiu um comunicado ${ }^{7}$ que reforçava a necessidade de contribuir para a aplicação do Quadro de Acção de Hyogo no espaço europeu e apoiar a realização dos objectivos de desenvolvimento do milénio nos países em desenvolvimento.

A evolução do pensamento internacional em matéria de redução de risco de desastres

A estratégia internacional para a RRD representou o culminar de um longo processo de reflexão que se concretizou em 2005 com o designado Quadro de Acção de Hyogo.

Acrescente preocupação internacional relativamente ao aumento de desastres, conduziu a Assembleia-Geral da ONU, em 1989, a aprovar a resolução 44/236 que designava a década de 90 como sendo, a Década Internacional para a Redução de Desastres Naturais (DIRDN). Este documento evidenciava uma atitude de optimismo e de convicção nos recursos técnicos e científicos disponíveis para enfrentar esta ameaça global, mediante uma acção internacional concertada.

Em 1994 ocorreu a $1^{\text {a }}$ Conferência Mundial sobre Prevenção de Desastres Naturais, na qual foi apresentado a Estratégia e Plano de Acção de Yokohama, que representa o primeiro plano para a criação de uma política de redução de desastres com orientações sociais comunitárias.
Concluída a DIRDN, as Nações Unidas criaram um secretariado permanente em Genebra, de modo a impulsionar a estratégia internacional para a redução de desastres (ISDR). A missão do secretariado do UN/ ISDR é de promover, no âmbito do desenvolvimento sustentável, uma maior consciência da importância da redução de desastres, de modo a tornar as comunidades mais resilientes aos riscos naturais.

Em 2002, o Plano de Implementação de Joanesburgo, identificou a necessidade de uma acção integrada, para múltiplas ameaças, dando prioridade às vulnerabilidades, à avaliação de riscos e à gestão dos desastres.

Em 2005, na Conferencia Mundial sobre Redução de Desastres, em Kobe/Japão, 168 países membros das Nações Unidas, entre os quais Portugal, adoptaram, a Declaração de Hyogo e o Quadro de Acção 2005-2015: Construir a Resiliência das Nações e das Comunidades face aos desastres.

Estes dois documentos, de natureza política, afirmam por um lado a responsabilidade dos estados em proteger as populações dos desastres, por outro lado apresenta o pensamento estratégico internacional concebido de modo a promover a emergência de uma cultura de prevenção baseada na redução das vulnerabilidades.

\section{A Estratégia internacional para a RRD: 0 Quadro de Acção de Hyogo}

O Quadro de Acção de Hyogo foi formulado, tendo em conta um conjunto de acções globais e orientadas para responder ao impacto dos desastres a nível nacional.

Basicamente a estratégia internacional é constituída por um conjunto de cinco prioridades correlacionadas por um conjunto de actividades essenciais e definidas pelo Quadro de Acção.

$1^{a}$ Prioridade: Garantir que a RRD seja uma prioridade nacional através de um mecanismo institucional designado por Plataforma Nacional para a Redução de Risco de Desastres.

A primeira prioridade aborda a dimensão política.

o compromisso político é determinante para promover a RRD e implementar o Quadro de Acção de Hyogo. Esta primeira prioridade reflecte a necessidade de uma vontade política em participar, enquanto membro das Nações Unidas, no movimento global de construção da resiliência face aos desastres.

Actividades essenciais:

- Quadro institucional e legislativo nacional (implementação da Plataforma Nacional para a redução de risco de desastres);

- Recursos. 
$2^{a}$ Prioridade: Identificar, avaliar, monitorizar os riscos de desastres e melhorar os avisos atempados

A segunda prioridade aborda a dimensão científica.

Esta prioridade é fundamental como apoio à decisão e implica a necessidade de aprofundar e validar os conhecimentos relacionados com as vulnerabilidades físicas, sociais, económicas e ambientais, e saber como estas vulnerabilidades podem evoluir a curto e médio prazo. Devido às lacunas identificadas, dois tipos de actividades foram consideradas essenciais.

Actividades essenciais:

- Avaliação dos riscos a nível nacional e local;

- Avisos atempado.

$3^{a}$ Prioridade: Construir uma cultura de segurança e de resiliência, através do conhecimento, da inovação e da educação

A terceira prioridade aborda a dimensão social.

Baseado no entendimento que o risco de desastres nunca é nulo, mas pode ser reduzido ou atenuado quando as populações estão devidamente informadas e quando elas adquirem uma cultura de prevenção, esta prioridade permite tornar as populações agentes activas do processo de prevenção e de recuperação dos desastres, facultando um maior controlo sobre os acontecimentos extremos.

Actividades essenciais:

- Gestão e partilha de informação;

- Educação e a formação;

- Pesquisa;

- Sensibilização do público.

\section{$4^{a}$ Prioridade: Reduzir os factores de risco subjacentes}

A quarta prioridade aborda a dimensão das vulnerabilidades.

O risco de desastres não está apenas associado a ocorrência de eventos extremos, mas essencialmente à forma como estes fenómenos interagem com o espaço construído pelo homem. Este assunto foi de tal forma debatido, que no final da Década Internacional, na sequência de uma recomendação da Nações Unidas, foi abolido o adjectivo "natural" diante do substantivo desastre, com base no entendimento, que os desastres são a consequência de uma associação entre os evento naturais e as vulnerabilidades sociais e humanas ${ }^{8}$. Nesta lógica, a ocorrência de um furacão no meio do mar ou a destruição de uma ilha deserta desabitada, não são considerados desastres, apenas eventos naturais. 0 conceito de desastre surge associado fundamentalmente aos danos que provocam os eventos extremos sobre o homem e os seus bens.

As actividades essenciais:

- A gestão ambiental e os recursos naturais;
- As boas práticas em matéria de desenvolvimento social e económico;

- O desenvolvimento do território e a adopção de medidas técnicas adequadas.

$5^{a}$ Prioridade: Reforçar as estratégias de preparação face aos desastres

A quinta prioridade aborda a dimensão da acção de emergência face aos desastres.

É possível limitar, consideravelmente, as consequências dos desastres e das perdas se as autoridades competentes, os cidadãos e as comunidades estiverem dotadas de um conjunto de conhecimentos e de capacidades que lhes permitam gerir e reagir eficazmente durante e após o desastre.

A preparação pode englobar vários tipos de medidas ou de actividades, tais como, os planos de emergência, a constituição de stocks de material e de alimentos, os serviços de urgência e os dispositivos de permanência, a questão tão importante das comunicações, da distribuição da rede eléctrica, dos mecanismos de gestão e de coordenação de informação, a formação de pessoal, os exercícios colectivos e a educação do público.

Este tipo de actividade permite fazer a diferença e assegurar a coerência entre as actividades de gestão de desastres, competências da Protecção Civil, e garantir a coerência e a complementaridade entre as esferas humanitárias e do desenvolvimento, nomeadamente através da criação ou extensão de capacidades nacionais para conduzir actividades de avaliação dos prejuízos.

As actividades essenciais:

- Reforçar capacidades de gestão em situação de desastre;

- Apoiar o diálogo interinstitucional;

- Fundo de calamidades/desastres.

O conceito de Plataforma Nacional de Redução de Risco de Desastre

A implementação do Quadro de Hyogo implica a criação de um mecanismo integrado de RRD multisectorial para coordenar os diferentes sectores, designado por Plataforma Nacional para a Redução de Risco de Desastres.

A Plataforma Nacional é o ponto nevrálgico da estratégia internacional da RRD, uma vez que ela representa o elemento catalizador de toda a actividade nacional de redução de risco.

De acordo com o Secretariado do ISDR o conceito de Plataforma Nacional, pode ser definido, como sendo um fórum ou uma comissão, composto por grupos multisectoriais, com o desígnio de promover a RRD de forma integrada, que advoga em favor da RRD.

Neste sentido, a Plataforma Nacional surge como um espaço privilegiado, onde a coordenação em torno de 
áreas prioritárias requer acções concertadas e processos de participação. Tal como ela foi concebida a nível internacional, a Plataforma Nacional pretende ser um instrumento de coordenação transversal, de modo a beneficiar plenamente a actividade agregada em torno da RRD, e em consonância com o Quadro de Acção de Hyogo ${ }^{9}$. Embora cada país tenha alguma autonomia para definir a estrutura da sua Plataforma Nacional, o modelo está regulamentado no Quadro de Acção de Hyogo 20052015 e é monitorizado pela Plataforma Global (ISDR) que promove um movimento mundial de RRD. O número de Plataformas Nacionais em todo o mundo está a aumentar. Em 2007, a Plataforma Global era constituída por 115 Plataformas Nacionais e os dados recentemente divulgados pelo ISDR, indicaram que em 2008/2009 aderiram mais 9 países.

No espaço europeu, 12 países implementaram Plataformas Nacionais (Bulgária, República Checa, França, Alemanha, Hungria, Itália, Espanha, Suécia, Suíça, Rússia, Reino Unido e Áustria) e alguns desses países desenvolveram actividades reconhecidas como boas práticas. Destacam-se alguns casos a título exemplificativo.

República Checa:

- Elaborou uma nova legislação na qual integrou a RRD e estabeleceram uma rede de informação junto dos países vizinhos.

França:

- Elaborou mapas de risco em 5.000 comunidades;

- Integrou a RRD na Educação;

- Organizou conferências com a participação das Plataformas Nacionais europeias sobre redução RRD.

Alemanha:

- Preparou a posição da Alemanha e da União Europeia sobre RRD junto da WSSD (World Summit on Sustainable Development);

- Organizou duas reuniões sobre "The Early Warning Conferences";

- Organizou duas reuniões sobre Plataformas Nacionais europeias;

- Realizou um estudo encomendado pelo ADPC (Asian Disaster Preparedness Center) sobre a possibilidade de implementar três Plataformas Nacionais no Sudeste asiático.

Hungria:

- Formou voluntários para integrar missões internacionais no quadro da INSARAG (International Search and Rescue advisory Group) adoptado pelo OCHA (Office for the Coordination of Humanitarian Affairs).

Suíça:

- Elaborou uma avaliação de risco para a Suiça;

- Desenvolveu a "Swiss strategy for the protection against natural hazards".

\section{Conclusão}

A estratégia internacional de redução de desastres é uma estrutura global em rede, constituída por um sistema de Plataformas Nacionais que têm como objectivo desenvolver a nível nacional, um conjunto de disposições politicas, legais, sociais e técnicas no sentido de advogar a redução de vulnerabilidades para enfrentar a ameaça global dos desastres.

No entanto, observa-se que a intensa actividade, levada a cabo pela comunidade internacional, no sentido de encontrar respostas para enfrentar esta ameaça, não se traduz na prática, com raras excepções, pela acção dos governos em dotar os seus territórios, dos instrumentos considerados essenciais a nível internacional para a RRD. É com alguma preocupação que continuamos a assistir aos impactos destrutivos dos desastres, deixando rastos semelhantes a cenários de guerra.

Para a comunidade internacional, para além das perdas humanas insubstituíveis, os desastres comprometem gravemente a curto prazo os investimentos de desenvolvimento sustentáveis, e quando esses investimentos não contemplam medidas de RRD, como aconteceu recentemente com o sistema de distribuição da rede eléctrica em França, após a passagem da tempestade Klau, correm o risco de se tornarem mais uma vulnerabilidade a adicionar à muitas outras, alimentando desta forma, o ciclo das vulnerabilidades gerado pelo nosso modelo de desenvolvimento.

A resposta da comunidade internacional para enfrentar esta ameaça, implica a emergência de uma cultura de prevenção que possa tornar as comunidades mais resilientes ao fenómeno.

Apesar das incertezas, sabemos que a Natureza não vai negociar connosco. A sociedade humana deverá aprender a viver com o risco dos eventos naturais. Se por um lado, podemos efectivamente aprender, por outro lado cabe aos governos a responsabilidade de proteger as pessoas e os seus territórios dos efeitos adversos e aleatórios dos eventos extremos, mediante o cumprimento do Quadro de Acção de Hyogo 2005.

É certo que os desastres são uma ameaça à segurança e bem-estar das populações, no entanto, face a esta ameaça, é fundamental perceber que não somos impotentes. Podemos aprender a reduzir os efeitos dos impactos adversos, podemos aprender a adaptarmo-nos, podemos aprender a protegermo-nos, podemos ainda aprender a lidar com a Natureza, de modo a tornar as nossas comunidades menos vulneráveis, se tivermos acesso aos instrumentos apropriados e às estratégias validadas.

Raymond Aron escrevia em 1960 que os tempos difíceis convidam à meditação; ele não se referia a uma meditação contemplativa, mas uma meditação orientada para respostas concretas de modo a enfrentar as situações adversas e reduzir a nossa incerteza perante o futuro. 
Aceitar o desafio da emergência de um novo paradigma, pondo em causa os nossos conhecimentos, as nossas certezas e as nossas justificações, pode ser menos angustiante do que enfrentar o futuro à margem da ESTRATÉGIA INTERNACIONAL DE REDUÇÃO DE DESASTRES.

\section{Referências}

ISDR: Hyogo Framework for Action 2005-2015: Building the resilience of nations and communities to disasters. 2005.

ISDR: Words Into-Action: A guide for implementing the Hyogo Framework. 2007.

ISDR: Living with the Risk: A global review of disaster reduction initiatives. 2004.

UN/ISDR: Guidelines for National Platforms for Disaster Risk Reduction. 2007.

DKKV: Disaster risk reduction in Europe. May 2008.

\section{Notas}

(1) GECHS- Disaster Risk Reduction, Climate Change Adaptation and Human Security Report 2008:3 (A Commissioned Report for the Norwegian Ministry of Foreign Affairs.

(2) IPCC, Climate Change 2007: Synthesis Report, Annex II

(3) UNFCCC Decision 1/CP.13; Bali Action Plan

(4) CRED

(5) CRED: EM-DAT

(6) CRED: Disaster Statistics Europe

(7) COM (2009) 84. 23.02.2009

(8) Definição dos termos usados na redução de risco de desastres: http://www.unisdr.org/eng/library/libterminology-eng.htm.

(9) UN/ISDR Guidelines National Platforms for Disaster Risk Reduction 